Since the establishment of the insurance fund, lawsuits, which used to number 200 a year, have fallen to 60 . In 1905 the accidents numbered 9,000; in 1909 they had fallen to 5,000, owing to greater care, improvement of methods, and mine inspection. The period of temporary invalidity after accident used to be twenty-five days; the year before last it was sixteen and a half days. " Injured miners receive pay from the first day of the accident. In consequence of the frequent visits of the official surgeons, whose report is final, malingering has been reduced to a minimum. An injured miner has one alternative, and that is to apply to a judge, who, if he deems it necessary; can send a doctor to examine the patient, and if the medical report is contrary to that of previous examiners, the judge may reopen the case and settle it. Lawsuits are tried in Caltanissetta and appeals are heard in Palermo.

The cost of the administration comes to 140,000 francs a year. The sum paid to injured workmen in 1905 was 700,000 francs; in 1909 it was 300,000 francs. M. Colojanni maintains that the terms arranged for the injured sulphur miners of Sicily are better than those for the ordinary miner in Germany.

The principal accidents are fracture of arms and legs due to falls of stone from the roof, fractures of the bones of the feet and injuries to the head by falls of stone. Beyond conjunctivitis due to irritation of the eyelids by sulphurous. acid and sulphuretted hydrogen, eye affections are not common. Trachoma is sometimes met with. The men are occasionally asphyxiated through unexpectedly inhaling sulphuretted hydrogen and carbon dioxide gases given off from the bituminous clay and the naked lights used in the mine by the men and boys.

The carussi frequently fall down the steep and worn steps which lead into the mines. Of the 5,000 accidents which occur annually, 1,200 happen to these boys; 50 per cent. of the accidents occur among the piconniers, and 26 per cent. among the carussi. Of the latter 2 per cent. are fatal.

An Invalid Fund has been or is about to be opened for the sulphur miners. This will be managed by the State. To it owners and leaseholders will contribute 1.5 francs per ton of sulphur. It is stated that this fund will not be contributed to by the workmen.

Of the good results which have followed the introduction of the Accident Insurance Fund among the sulphur miners of Sicily I again repeat that I cannot speak too highly.

\section{EXPERIMENTS ON THE RESTORATION OF PARALYSED MUSCLES BY MEANS OF NERVE ANASTOMOSIS.*}

BY

ROBERT KENNEDY, M.A., M.D., D.Sc.

SURGEON TO THE WESTERN INFIRMARY, GLASGOW, AND LECTURER ON APPLIED ANATNMY IN THE UNIVERSITY.

\section{[ABstract.]}

Restoration of voluntary co-ordinated movements after "nerve crossing," first demonstrated by Flourens, has since been from time to time the subject of investigation. The conclusions of Flourens have been confirmed by Rawa, Stefani, Howell and Huber, Langley, and myself. A practical application in surgery was first suggested by Létiévant, and within the past twelve years considerable development has taken place in this direction.

During the past two years I have performed about 30 experiments on monkeys and dogs in order to investigate several points from the physiological standpoint. These experiments fall naturally into three groups. The first deals with the methods of cross union or anastomosis between the peripheral'segment of a divided facial nerve and a suitable motor nerve in the neighbourhood. The second series of experiments deals with anastomosis in the fore limb of dogs, in order to investigate some aspects of the question not overtaken by previous work on this part of the subject. The third series deals with the brachial plexus, its functions, and the methods of anastomosis applied to it.

The present communication is confined to an account of

* A paper read before the Royal Society on June lst. The expense of this research has been defrayed bv a Government grapt from the Roval.
Society. experiments with the facial nerve, of which there have been 10 performed. Of these 10,6 were primary anastomoses and 4 secondary, anastomoses - that is to say, in 6 the facial was cut, and its peripheral segment immediately anastomosed with the central segment of the substitute nerve, while in 4 the facial was cut and left unattached for a period, precautions to prevent spontaneous reunion being takon, and then at the end of that period re-exposed and united to the substitute nerve.

Primary Anastomosis.

In the primary anastomoses two were in monkeys and four in dogs. Of the two monkeys, in one the facial was cut and attached to the side of the spinal accessory, and in the other it was attached to the side of the hypoglossal nerve. Voluntary dissociated movements of the face commenced to return-in the former in 58 days, and in the latter in 32 days, and each of the animals had complete veluntary closure of the eye at about 100 days.

Of the four dogs, in two the spinal accessory was the substitute nerve, and in two the hypoglossal. Of the two spino-facial anastomoses one was an end-to-side and one an end-to-end, and the same variation was practised with the two hypoglosso-facial anaistomoses.

The two spino-facial anastomoses commenced to recover voluntary dissociated movements of the face at 105 (end to side) and 90 (end to end) days respectively, and were almost complete as regards power to close the eye at 116 and 123 days respectively.

The two hypoglosso-facial anastomoses commenced to recover power to close the eye at 55 (end to side) and 84 (end to end) days respectively, and were very complete as regards closure of the eye at 142 and 107 days respectively.

Association movements of the face, on the normal distribution of the substitute: nerve being innervated by the animal, were observed only in two of the experiments, one a spino-facial (end to side) in a monkey, and one a hypoglosso-facial (end to side) in a dog. In the latter case, every rapid movement of the tongue, as in eating, licking the lips, etc., was accompanied by a wink.

Secondary Anastomosis.

The secondary anastomosis experiments were performed in one monkey and three dogs. The monkey had spinofacial anastomosis (end to end) performed one month after section "of the facial, and commenced to recover power to close the eye by means of the orbicularis at 46 days, and there was good reflex closure of the eye at 65 days.

In the three dogs the facial nerve was cut close to the stylo-mastoid foramen and precautions taken to prevent reunion, and anastomosis performed after the lapse of one month in two of the dogs, and after 100 days in the remaining dog. Of the two in which the interval of one month had elapsed, in one, a spino-facial (end to end) anastomosis, no recovery of voluntary function had taken place at 69 days, when the animal died. In the other in which a month's interval had elapsed, a hypoglosso-facial (end to end) anastomosis, voluntary dissociated closure of the eye commenced to return at 60 days and was complete at 93 days.

In the dog in which 100 days elapsed before substitution, an end to end spino-facial anastomosis was performed, and voluntary closure of the eye commenced to return at 124 and was complete by 167 days.

In every case except two a physiological examinaticn was made, and proved that the recovery of movements which had taken place in the face was wholly due to impulses reaching the face via the substitute nerve. In both cases in which the examination was not made before death the animals died unexpectedly. In one of these no voluntary function had returned (dog), and in the other, in which restoration had taken place (monkey), the postmortem examination showed that there had been no reunion with the central end of the facial, as the stylomastoid foramen was found completely obliterated by a bone plug which bad been hammered into it at the operation.

As an addendum, reports of two cases of spino-facial anastomosis are given. The first is a report twelve years after the operation performed in a woman, and published in the Philosophical Transactions in 1901, in order to show the ultimate result. The second is a report of a case of facial paralysis of three years' standing in 
which spino-facial anastomosis was performed, and in which recovery commenced about three years after the operation.

\author{
Conclusions.
}

The following general conclusions follow from the observations which are recorded in the full paper:

1. In any case of facial paralysis due to division or compression of the facial nerve, the best procedure, should spontaneous recovery fail, or be deemed impossible, is to attempt restoration of the damaged nerve.

2. Should efficient restoration of the nerve be impossible or be deemed impossible, anastomosis with the spinal accessory or hypoglossal holds out the most favourable prospects of recovery, given that the facial muscles are still recoverable from the point of view of duration of complete severance from the nutritive influence of the central nervous system.

3. Of the two substitutes, spinal accessory and hypoglossal, when the latter is used the restoration appears to commence sooner, but there does not seem to be a great difference in the ultimate result of the two substitutes, as far as the recovery of the face is concerned.

4. Of the new paralysis produced as a result of cutting the substitute nerve that which is produced when the spinal accessory is cut is much less objectionable than that produced when the hypoglossal is cut, and when the paralysis is to be left as a permanent defect, namely, when the peripheral segment of the substitute nerve is to be left unattached, the hypoglossal paralysis is not justifiable.

5. When, in consequence of the anastomosis, association movements are present in addition to voluntary co-ordinated and dissociated movements, these associated movements give no trouble and are not noticeable with ordinary movements when the sjinal accessory has been used, but, if present, may be most objectionable and noticeable with ordinary movements when the hypoglossal has been used.

6. As regards the interval during which the paralysis has lasted before anastomosis has been performed, there appears to be no difference in the date of commencing recovery and ultimate result, whether anastomosis immediately follows section of the facial, or whether one month's interval at least is allowed to elapse before the anastomosis is performed after the facial has been cut.

7. The only way to make an efficient union between two nerves is completely to cut across all the nerve fibres in both nerves; methods such as Manasse's, designed to maintain the integrity of the nerve fibres, give inefficient unions.

8. In the course of recovery of independent voluntary co-ordinated movements, the orbicularis palpebrarum is first to exhibit recovery, and usually is the muscle which recovers best, and in no case has a perfect recovery in the movements of the face been proved to take place.

9. Reunion of the facial nerve is to be preferred to restoration by means of an anastomosis, as the latter involves interference with the distribution of another nerve, and association movements are sometimes troublesome.

10. The distribution of the facial nerve is, in dogs and monkeys, limited to its own side of the face, and recoveries cannot therefore be attributed to a supply from the opposite facial.

11. The distal segment of the divided facial, except for a short period immediately following division, on being irritated gives no response in the muscles, if no connexions at a subsequent date have been made with the centres, eifier through its own central segment or by some other path, and, conversely, the occurrence of muscular responses on irritating the peripheral segment is proof that such connexions have been established.

Dr. Kennedy has kindly furnished us with the following details of the two cases referred to in his paper:

Case I.-Section of Facial Nerve: Spino-facial ANASTOMOSIS.

A. Abstract of Report published in "Phil. Trans." in 1901.

In a woman, aged 46, the right facial nerve was divided for the relief of severe facial spasm, and spino-facial end to side anastomosis was immediately performed for the cure of the facial paralysis produced by the section of the facial.

Recovery of the orbicularis palpebrarum commenced on the forty-ninth day, and gradual improvement took place. At a year and a quarter she could voluntarily completely close the 4 right eye. The right side of the forehead could be very slightly moved and inco-ordinated movements of the cheek and mouth could be made. In blowing, the aperture of the mouth could not be made circular. In repose there was no sign of facial not be madr

All these movements were independent of those of the shoulder, and it was only after a year and a quarter that it was discovered that association movements were present; but it was only at the moment of suddenly and violently raising the arm that association movements were present, and they passed off although the arm was continued to be held up.

\section{B. Present Condition.}

(a) Electrical Examination.-All the muscles of the right side of the face give normal faradic responses both when irritated through the nerve and directly. The minimal responses are evoked by very nearly the same strength of current. The same is found in the sterno-mastoid and trapezius. The responses to the galvanic current are also normal quantitatively and qualitatively.

(b) Movements.-Further improvement has taken place in the facial movements, especially as regards the lower part of the face. The eye at present can be completely closed voluntarily with some degree of tightness and quite independently of shoulder movements, as was the case in 1901. Winking takes place synchronously in the two eyes. The lips can form a place synchronously in the two eyes. The lips can form a be filled with air under pressure without any escaping between the lips. On compressing the cheeks it is through the right side of the mouth that the escape takes place. Food does not tend to collect between cheek and gums. There is still defective movement in the muscles of the right side of the forehead. Smiling is possible without showing much defect, but any extreme emotional movement brings out asymmetry.

As regards the present state of the association movements, these are exhibited only on violent elevation of the shoulder, but pass off quickly, and the shoulder can be kept held up without any association movements showing in the face.

Case il.-Facial Paralysis (Otitis) : Spino-facial

ANASTOMOSIS.
In this case the patient, a girl aged $3 \frac{1}{2}$ years, had suffered from left-sided facial paralysis since 6 months old in consequence of otitis media. In the course of the otitis media there had been an infection in the neck, which had destroyed the function of the left spinal accessory.

When the case was first seen there was typical left-sided facial paralysis. The eye could not be closed, but the eyeball was rolled upwards on attempts at closure being made. The cheek was flaccid, and the left angle of the mouth drooping.

At the operation on April 25th, 1907, no responses in the muscles could be got by stimulating the exposed facial nerve, but trivial responses were got in the muscles by stimulating them directly on the muscle substance by the galvanic current.

The spinal accessory central segment was identified anatomically, in the absence of all electrical responses, due to the lesion. It was cut, turned up, and attached to the peripherai segment of the facial, previously also divided-that is, an end to end union was made.

No improvement resulted for three years, when the eye began to show voluntary closure. This advanced, and now at four years the eye can be voluntarily closed almost completely, and there is no irritation of the conjunctiva, as foreign bodies do not readily get access to the eye, the winking movements being efficient.

Other facial muscles have also developed, and the lips can be held close together, so as to prevent the escape of air held in the mouth under pressure. On compressing the distended cheeks the air escapes by the mouth with a report. There is but little appearance of facial paralysis in repose.

No association movements can be discovered

There has not been any satisfactory electrical examination since the operation, as it is necessary for this to have the child under an anaesthetic.

$$
\Longrightarrow
$$

$\mathbf{A}$

\section{SUBTEMPORAL DECOMPRESSION OPERATION FOR INTRACRANIAL PRESSURE.}

BY JOHN STEWART, M.B., C.M., HONORARY SURGEON, BATLEY DISTRICT HOSPITAT.

CASES of recovery from this operation are still sufficiently rare to make this one of interest. It is also worth recording on account of the case being under close observation from the time of the injury and the interesting development of signs and symptoms leading up to the operation.

A man, aged 37, was admitted at 12.30 on March 10th. He and a fellow workman had been injured by the fall of a crane. The fellow workman was at once in a desperate condition. The crane had fallen across his chèst, fracturing several ribs, which crushed into his lungs. When the ambulance wagon arrived 